\title{
“SAFETY AND SECURITY" EM INSTITUIÇÕES HOTELEIRAS EM TER
}

\author{
Pedro Simões \\ Instituto Superior da Maia - ISMAI \\ CEDTUR - Centro de Estudos de Desenvolvimento Turístico
}

\begin{abstract}
Resumo: O Turismo em Espaço Rural (TER) tem-se vindo a impor-se como actividade com potencial para relançar o desenvolvimento sustentável de algumas zonas deprimidas, nomeadamente daquelas que têm, todavia, recursos com elevada qualidade cultural ou natural. A sustentabilidade é, pois, um conceito chave para esta modalidade de turismo, porquanto se não houver um processo de desenvolvimento sustentável hipoteca-se o que de mais valioso estes territórios albergam. Neste contexto, e devido ao aumento dos níveis de criminalidade em Portugal, não só nos grandes centros, mas também em zonas rurais ou com menos recursos, pode desestabilizar-se a procura turística. Por essa razão, apresenta grande acuidade o fortalecimento de acções de safety and security em instalações hoteleiras de TER plasmadas na dinamização da prevenção e na articulação com as forças policiais, em ordem ao reforço da segurança do TER.
\end{abstract}

Palavras-chave: Turismo, Segurança, Meio Rural

\begin{abstract}
Safety and security" in hospitality tourism in rural area
The rural tourism Areas (RTA) has been imposed as an activity with the potential to boost the development of some rural areas, particularly those who have resources with high quality cultural or natural. However, sustainability is a key concept for this type of tourism, because if there is a process of sustainable development mortgage is what is most valuable harbor these territories. In this context, and due to increased levels of crime in Portugal, not only in large cities, but also in rural areas or with fewer resources, can help to decrease the number of tourists to take advantage of our tourist offer. For this reason, it is essential the increase of strenght action of safety 'nd security methods among hotel facilities in Tourism at Rural Area, ie, the one hand, the dynamics of prevention, and secondly, the connection fortelecimento the local police for help eradication of this phenomenon.
\end{abstract}

Keywords: Tourism, Security, Rural Areas.

Resumen: Seguridad personal y protección en las instituciones hoteleras del turismo en espacio rural 
El turismo en espacio rural (TER) se ha ido imponiendo como una actividad con potencial para impulsar el desarrollo sostenible de algunas zonas deprimidas, en particular las que tienen todavía recursos con una alta calidad cultural o natural. La sostenibilidad es, por lo tanto, un concepto clave para esta modalidad de turismo, ya que si no hubiera un proceso de desarrollo sostenible se hipotecaría lo más valioso que albergan estos territorios. En este contexto, la demanda turística puede llegar a desestabilizarse no sólo en las grandes ciudades, sino también en las zonas rurales o con menos recursos, debido al aumento de los niveles de criminalidad en Portugal. Por esta razón, es esencial fortalecer las medidas de seguridad personal y protección (safety and security) en las instalaciones hoteleras del TER, plasmadas en la dinamización de la prevención y en la coordinación con las fuerzas policiales, con el fin de fortalecer la seguridad de este tipo de turismo.

Palabras clave: Turismo, seguridad, medio rural

\section{O TURISMO EM ESPAÇO RURAL}

O Turismo no Espaço Rural é definido como um conjunto de actividades e serviços prestados a troco de remuneração, de forma personalizada e de acordo com os valores, tradições e modos de vida das comunidades rurais em que se insere, apresenta características próprias, não tendo nada em comum com as modalidades convencionais de turismo.

Esta actividade tem como objectivo principal oferecer ao turista a oportunidade de reviver as práticas, os valores e as tradições culturais e gastronómicas das sociedades rurais, com um acolhimento personalizado e lucrativo com a sua hospedagem. Visto pela perspectiva do desenvolvimento rural leva-nos a concluir que o turismo em espaço rural é uma das actividades mais bem colocadas para assegurar a revitalização da economia rural, sendo tanto mais forte, quanto conseguir endogeneizar os recursos, a história, as tradições e a cultura de cada região. Não é só um factor de diversificação das actividades agrícolas mas também um factor de pluriactividade, através da dinamização de um conjunto de outras actividades económicas que dele são tributárias e que com ele interagem.

É o caso do artesanato, da produção e venda na exploração de produtos tradicionais, dos quais se destacam os produtos agrícolas e géneros alimentícios certificados, dos serviços de transporte, de animação, de guias etc.

O que interessa é promovê-lo de forma harmoniosa e sustentada, tendo respeito pelas diferenças que caracterizam cada região e pelos requisitos de qualidade e de comodidade exigidos pelos turistas que o procuram.

Foi com base nestes pressupostos que foram adoptadas por entidades nacionais um conceito de turismo em espaço rural, entendido como um produto completo e diversificado que integra as componentes de alojamento, restauração, animação e lazer, baseado no acolhimento hospitaleiro e personalizado e, repito, nas tradições mais genuínas da gastronomia, do artesanato, da cultura popular, da arquitectura, do folclore, e da história. 


\section{CARACTERÍSTICAS DO TURISMO EM ESPAÇO RURAL}

Situado sempre em zonas rurais compreendidas como as áreas com ligação tradicional e significativa à agricultura ou ambiente e paisagem de carácter vincadamente rural; Considerado como um conjunto de actividades e serviços realizados e prestados mediante remuneração em zonas rurais, segundo diversas modalidades de hospedagem, de actividades e serviços complementares de animação e diversão turística, com vista a proporcionar aos turistas uma oferta completa e variada; À escala rural do ponto de vista da dimensão e das características arquitectónicas e dos materiais construtivos típicos da região; Ligado às estruturas sociais ditas tradicionais, isto é, as que conservam as características gregárias, os valores, modos de vida e de pensamento das comunidades rurais baseadas em modelos de agricultura familiar; Sustentável, na medida em que o seu desenvolvimento deve ajudar a manter as características rurais da região, utilizando os recursos locais e os conhecimentos vindos do saber das populações e não ser um instrumento de urbanização; Diferenciado de acordo com a diversidade do ambiente, da economia e com a singularidade da história, das tradições e da cultura populares.

\section{O INTERESSE PELO TURISMO NO ESPAÇO RURAL}

O Turismo Rural não é algo acidental ou temporário, resultado da evolução do modelo da sociedade pós-moderna em que vivemos.

Em termos gerais, os indicadores apontam para um crescimento regular da procura dessa actividade, por parte de uma clientela de nível cultural e poder económico superior à media, exigente na qualidade, e em busca das diferenças e em busca das diferenças que o tornam atraente face às restantes modalidades de turismo.

No entanto, não é só esta clientela de gama alta que procura este tipo de turismo. Actividades como a caça, pesca, feiras e romarias, cultos religiosos, festivais de folclore e gastronómicos, atraem turistas, oriundos de todo o tipo de estratos socioeconómicos.

Importa, pois, que a oferta deste segmento de turismo seja capaz de fornecer respostas que se adequam aos diferentes tipos de necessidades, bem como às solicitações provenientes dos diferentes estratos etários que, por razões distintas, são atraídas ou susceptíveis de vir a ser aliciadas, para esta forma de turismo.

\section{TURISMO E CRIME EM ÁREAS RURAIS}

O conceito mais abrangente que o conceito "crime" engloba os factos qualificados legalmente como crimes, cometidos por indivíduos ou por associações espontâneas de indivíduos, bem como os comportamentos anti-sociais de vários tipos que, sem assumir a forma de uma infracção penal, podem, numa situação de acumulação, criar ou contribuir para um clima de tensão e de insegurança. 
A criminalidade organizada inclui crimes cometidos de forma regular e em que as vítimas são facilmente identificáveis. Os delitos são normalmente cometidas contra a propriedade e envolvem frequentemente violência física. (...) Falamos de padrões criminológicos, registados em áreas rurais, muito idênticos ao tipo de crimes registados nas principais cidades portugeusas.

Tendo em linha de conta o explanado, é a natureza do alvo que estabelece a principal diferença neste tipo de crime. A execução do crime nas zonas rurais; o facto de se assitir a um cenário de plantações e utilização de máquinas agrícolas, algumas de grande porte, em locais remotos, a que se pode juntar a falta de acesso e recursos para lidar com a desordem, são razões mais do que suficientes para os criminosos conseguirem executar os seus intendos."

O que faz a diferença é, em parte, a natureza do alvo, em crime rural, por exemplo, é a extensão de plantações e utilização de máquinas em locais remotos, assim como, a falta de acesso e de recursos para lidar com o crime e desordem.

Hoje em dia, a maioria da vida rural é construída na confiança e do impacto sobre uma grande parte da comunidade que compartilham dessa confiança mútua. Nas aldeias, todos se conhecem, estabelecendo uma ajuda real para as forças policiais, que, rapidamente, podem ter acesso a informações importantes sobre habitantes usuais, sua localização, sendo esta uma ajuda essencial na definição de eventuais criminosos.

Quem conhece o interior de Portugal está longe de imaginar que a paz das cidades e aldeias está a ser ameaçada, por uma vaga de criminalidade grave que tem vindo a assolar lugares outrora intocáveis pelos "males das grandes cidades".

A publicitação recente de dados policiais, em grande parte divulgados pelo OSCOT, publicados pelo matutino "Diário de Notícias", dá a conhecer que cerca de $80 \%$ da criminalidade violenta ocorre nos distritos de Lisboa, Porto, Setúbal e Faro, mostrando que as cidades do Interior estão a ser o novo alvo dos criminosos.

$\mathrm{Na}$ relação entre turismo e crime, existem dois pontos de vista aceites: um deles visa o estabelecimento de uma relação directa entre o aumento do número de crimes e o aumento do de turistas no destino. Neste caso, o Turismo de massas pode ser o exemplo mais evidente desse facto. Existem, ainda, outros factores importantes na vitimização dos turistas, tais como: as características étnicas, a escolha do tipo de alojamento, a idade, viajar só ou acompanhado, o género, a nacionalidade, entre outros (Albuquerque, 1999).

Convém, ainda, referir que, quando comparada a relação entre crime turístico e sazonalidade, concluiu-se que crimes como roubos, furtos, raptos e homicídios, aumentam significativamente em períodos denominados de "época alta" (Holcomb e Pizam, 2006) comparativamente a outros períodos do ano. É realmente na época alta que se junta maior número de turistas, muitas pessoas de origem e culturas diferentes, causando actuações díspares. Por exemplo, a cidade de Albufeira, Algarve, Portugal, é normalmente habitada por 30 mil pessoas, no entanto, nos meses de época alta chega atingir 400 mil pessoas.

O Turismo, ao estabelecer junção de pessoas de culturas diferentes num mesmo espaço geográfico que lhes é desconhecido, estabelece uma relação interactiva entre diferentes partes, a saber: o turista, o local, os residentes, a indústria turística e os 
serviços em geral. Contudo, o seu crescimento da actividade turística tem conduzido, na generalidade dos destinos, a um aumento significativo de incidentes de segurança, traduzidos na maior oportunidade de crimes, sobretudo económicos (roubos, fraudes), crimes de ofensa corporal, sexual, entre outros. Este facto deve-se, principalmente, a seis grandes factores:

1) O turista ser alvo preferencial pelo facto de, na generalidade, se fazer acompanhar de mais dinheiro ou outro tipo de valores e transportá-los visivelmente em público e de forma descontraída;

2) O turista, na generalidade, ignora as precauções normais de segurança.

\section{CONCLUINDO:}

As novas tendências para as zonas rurais aportam novos desafios mas também grandes oportunidades. A abordagem a estas novas tendências deverá ser sempre selectiva, isto é, regiões com características e níveis de desenvolvimento relativamente idênticos deverão ser tratados de forma idêntica pois só assim se obterão sinergias relativamente ao caminho mais correcto a seguir.

As TER, situadas em grande parte em áreas rurais, oferecem aos seus consumidores serviços de elevada qualidade, situação que para se manter futuramente deve ser acompanhada de um alto nível securitário.

A prevenção da criminalidade abrange todas as medidas destinadas a reduzir ou a contribuir para a redução da criminalidade e do sentimento de insegurança dos cidadãos, tanto quantitativa como qualitativamente, quer através de medidas directas de dissuasão de actividades criminosas, quer através de políticas e intervenções destinadas a reduzir as potencialidades do crime e as suas causas. Inclui o contributo dos governos, das autoridades competentes, dos serviços de justiça criminal, de autoridades locais, e das associações especializadas que eles tiverem criado na Europa, de sectores privados e voluntários, bem como de investigadores e do público, com o apoio dos meios de comunicação.

Apesar dos níveis de violência registarem algum aumento, especialmente em zonas rurais, contra idosos e pessoas sem defesa, e, por outro lado, também contra instalações hoteleiras em zonas menos movimentadas, as instituições devem consigo manter níveis securitários a montante (Safety) e ligações constante aos serviços de segurança da área (Security).

Sendo a junção da "Safety e Security" uma força patente na evolução securitária do Turismo em Portugal e no Mundo, muitos turistas, mesmo antes de viajarem, verificam os níveis de vulnerabilidade a eventuais roubos, assaltos e mesmo violações, nos locais para onde viajam.

A internet torna-se um meio de informação deveras utilizado para conhecer a evolução dos níveis de criminalidade nas zonas turísticas escolhidas e a forma como as polícias e outros serviços de segurança a montante actuam no combate ao crime. 
Tanto a Protecção Civil, Informações de Segurança (Intelligence) e o visionamento a montante de eventuais situações que possam levar à execução de algum crime, como uma boa actuação das forças policiais tanto na dissuasão e eventual ajuda na imobilização de eventuais criminosos, impedindo de executar as suas intenções, como na boa abordagem de investigação criminal, são razões mais do que suficientes para a manutenção e/ou aumento da segurança nas instalações hoteleiras em TER, para o incremento dos níveis de segurança em zonas mais desprotegidas, cuja distância de grandes centros e a diminuição de habitantes, podem levar à concretização de acções criminosas, destruindo meios físicos e mesmo provocando vítimas.

\section{BIBLIOGRAFIA}

Albuquerque, K. \& Mcelroy, J. (1999): “Tourism and Crime in the Caribbean", Annals of Tourism Research, Vol.26, Nº. 4, pp. 968-984.

Felson, M. (1998): Crime and Everyday Life, California,Pine Forge Press.

Felson, M. \& Clarke, R. (1998): Opportunity Makes the Thief: Practical Theory for Crime Prevention, Londres, RDS.

George, R. (2003): “Tourists 'perceptions of Safety and Security while visiting Cape Town", Tourism Management, 24(5), pp. 575-585.

Glensor, R. \& Peak, K. (2004): Crimes Against Tourists, USA, U.S. Department of Justice.

Garcia, Francisco Proença (2006): As ameaças transnacionais e a segurança dos Estados. Subsídios para o seu estudo. In Negócios Estrangeiro

Holcomb, J. \& Pizam, A. (2006): "Do Incidents of Theft at Tourist Destinations Have a Negative Effect on Tourists' Decisions to Travel to Affected Destinations?" In Y. Mansfeld \& A. Pizam (Eds.), Tourism, Security Safety: From Theory to Practice, Oxford, Butterworth-Heinemann.

Mawby, R. (2000): “Tourist's 'perceptions of security: The risk-fear", Tourism Economics, 6(29, pp. 109-121.

Messner, F. \& Golden, M. (1992): "Racial inequality and racially disaggregated homicide rates: An Assessment of alternative theoretical explanations", Criminology, 30, pp. 421-447.

Lowenthal D. (1996): Paysages et identités nationales. In: Jollivet, M., Eizner, N. (eds.). L'Europe et ces campagnes. Paris, Press de la Fondation Nationale de Sciences politiques: 245-274.

Moreira, F. J. (1994): O turismo em espaço rural. Enquadramento e expressão geográfica no território português. Lisboa, Centro de Estudos Geográficos.

Nash, D. 1996 (1976): Anthropology of tourism. New York, Pergamon.

Nilsson, P. A. 2002. Staying on farms. An Ideological Background. Annals of tourism research, 29 (1): 7-24.

OCDE (1994):Tourism strategies and rural development. Paris. 
Ochrym, R. (1990): "Street Crime, Tourism and Casinos: An Empirical Comparison", Journal of Gambling Studies, Vol. 6 (2), pp. 127-138.

Pizam, A. (1999): “A Comprehensive Approach to Classifying Acts of Crime and Violence at Tourism Destinations" Journal of Travel Research, 38; 5, pp. 5-12.

Tarlow, P, Muehsam, M. (1996): "Theoretical aspects of crime as they impact the tourism industry", in Pizam, A. \& Mansfeld, Y. (Eds) Tourism, Crime and International Security Issues, New York, Wiley. 